\title{
Influence of Blood Contamination on Bond Strength of a Self-Etching System
}

\author{
Ellen Cristina de Carvalho Mendonça ${ }^{a}$ \\ Samuel Nilo Vieirab \\ Fernando Aparecido Kawaguchic \\ John Powers ${ }^{d}$ \\ Adriana Bona Matos ${ }^{\mathrm{e}}$
}

\section{ABSTRACT}

Objectives: To detect the influence of blood contamination (BC) on the bond strength (BS) of a selfetching bonding system (SES) to enamel and dentine.

Methods: 25 human molars were longitudinally sectioned on the mesio-distal axis in order to obtain 50 specimens, which were embedded in acrylic resin. At first, the specimens were ground to expose a flat surface of enamel, and a bond strength test was performed. Afterwards, the samples were ground again in order to obtain a flat surface of dentine. Ten groups (total: $n=100$ ) were assigned according to substrate (enamel and dentine), step in the bonding sequence when contamination occurred (before the acidic primer and after the bonding resin), and contamination treatment (dry or rinse and dry procedure). Fresh human blood was introduced either before or after SES application (Clearfil SE Bond) and treated with air drying, or by rinsing and drying following application. Composite resin (Filtek Z-250,3M ESPE) was applied as inverted, truncated cured cones that were debonded in tension.

Results: The mean tensile BS values (MPa) for enamel/dentine were 19.4/23.0 and 17.1/10.0 for rinse-and-dry treatment (contamination before and after SES, respectively); while the measurements for the dry treatment, 16.2/23.3 and 0.0/0.0 contamination before and after SES, respectively.

Conclusions: It was determined that blood contamination impaired adhesion to enamel and dentine when it occurred after bond light curing. Among the tested contamination treatments, the rinseand-dry treatment produced the highest bond strength with BC after SES application, but it was not sufficient to recover the BS in the contamination-free group. (Eur J Dent 2010;4:280-286)

Key words: Blood contamination; Self-etching adhesive; Bond strength; Enamel; Dentine.

aDS, MS student at Department of Restorative Dentistry, School of Dentistry

University of Sao Paulo (USP), São Paulo, SP, Brazil.

b BDS, Department of Restorative Dentistry,

School of Dentistry University of Sao Paulo (USP),

São Paulo, SP, Brazil.

MS, PhD, Department of Restorative Dentistry,

School of Dentistry

University of Sao Paulo (USP), São Paulo, SP, Brazil.

d Department of Restorative Dentistry and Biomaterials, University of Texas Dental Branch at Houston, Houston, TX, USA.
BDS, MS, PhD, Associate Professor at Department of Restorative Dentistry, School of Dentistry University of Sao Paulo (USP), São Paulo, SP, Brazil.

- Corresponding author: Adriana Bona Matos Departamento de Dentística, Faculdade de Odontologia da Universidade de São Paulo (USP), Av. Lineu Prestes, 2227 - Cidade Universitária CEP 05508-900

São Paulo, SP, Brazil.

Phone/Fax: 55-11-37334307

E-mail: bonađusp.br 


\section{INTRODUCTION}

The use of a rubber dam is associated with high quality patient care and is currently the only way to achieve the dry field that is mandatory to accomplish excellence in composite resin restorations. However, in some clinical situations, this procedure is not always feasible; for example, when cavity preparations are located near or under gingival margins, ${ }^{1-7}$ and during the restoration of root and non-carious cervical lesions. ${ }^{8}$ Furthermore, only about $17 \%$ \%, 10 professionals routinely use the rubber dam. In this context, the contamination of the operatory field is a recurrent reality that emphasizes the value of studies in this area.

The influence of blood contamination on bond strength can be attributed to its high protein content that, along with macromolecules such as fibrinogen and platelets, can form a film on the dentine surface, obstructing the penetration of the adhesive system into dentine tubules. ${ }^{11}$

Recent studies ${ }^{12-18}$ report that hydrophilic adhesive systems are less sensitive to contamination with saliva than are hydrophobic bonding agents. However, the effects of blood contamination on the bond strength of these hydrophilic adhesive systems have not been entirely clarified. Additional studies $7,11,16,17,19-27$ have shown contradictory bonding results; contamination studies are somewhat difficult to understand due to their variable experimental design, such as the type of substrate tested, the particular step in the bonding sequence when contamination occurs, and the type of treatment that is performed in order to clean the operatory field; authors ${ }^{23}$ emphasize that these variables could play an important role in bonding results. It was observed that the majority of studies regarding blood contamination during adhesive procedure are related to the attachment of orthodontic brackets. ${ }^{2-6,24,25,28-32}$

Even though some treatments have been proposed in an effort to reverse the contamination effect - resurfacing with rotary instruments, ${ }^{7}$ rinsing with water followed by air drying, ${ }^{11,16,19,26}$ rinsing with water plus primer re-application, ${ }^{19,26}$ or re-etching with phosphoric acid ${ }^{11,16}$ - conflicting results were obtained. Hence, new studies are needed to establish a standard clinical protocol to counteract the effects of blood contamination. The demand for clinically simplified application techniques has increased the use of self-etching ad- hesive systems; therefore, the aims of this in vitro study are to determine the bond strength of a twostep self-etching adhesive to enamel and dentine in the presence of blood contamination, and to determine which contaminant treatment is capable of recovering adhesion.

\section{MATERIALS AND METHODS}

Twenty-five non-carious human molars were longitudinally sectioned through the mesio-distal axis using a low-speed saw (Isomet 1000, Buehler, Lake Bluff, Ill., U.S.A.); 50 specimens were obtained and embedded in self-curing acrylic resin (Sampl, Kwick, Buehler). Samples were ground flat with a series of silicon carbide discs until a $3 \mathrm{~mm}$ diameter enamel area was exposed. After performing an enamel bond strength test, the specimens were abraded again until the exposition of a flat superficial dentine surface, after which a dentine bond strength test was performed.

Specimens were randomly divided into 5 groups $(n=10)$ according to the following factors: the step in the bonding sequence when contamination occurred (before acidic primer or after bonding resin), and contamination treatment (dry or rinse-and-dryl. An enamel bond strength test was performed first, then the tooth surfaces were ground again in order to expose dentin; finally, a bonding test protocol was repeated. Table 1 and Figure 1 present the groups and a summary of the experimental protocol, respectively.

Fresh capillary blood was collected from the fingertip of a menopausal female. One drop of blood was applied directly to the surface of each specimen, and was left undisturbed for $15 \mathrm{sec}-$ onds. ${ }^{21}$

The rinse-and-dry treatment was performed via water spray $10 \mathrm{~cm}$ from the target tissue for 10 seconds, ${ }^{19}$ followed by a gentle blast of air until the substrate was completely dry. Conversely, the blot dry procedure was performed as a gentle air spray $10 \mathrm{~cm}$ from the target tissue for 20 seconds $^{26}$ in order to produce a dry layer of blood.

A two-step self-etching bonding system (Clearfil SE Bond, Kuraray, Tokyo, Japan) was applied as recommended by the manufacturer: the self-etching primer was applied for 20 seconds and the surface was gently dried with a mild air stream. Bonding resin was applied and lightcured for 10 seconds. 
A $3 \mathrm{~mm}$ diameter polytetrafluoroethylene mold was used to create an inverted, truncated cone of composite (Filtek Z-250, color A3 - 3M ESPE, U.S.A.), as described by Barakat and Powers. ${ }^{32}$ The composite was inserted in two sections, and each one was photocured for 20 seconds (Astralis 3, Ivoclar-Vivadent $A G$, Liechtenstein). All specimens were stored at $37^{\circ} \mathrm{C}$ in water for 24 hour before testing.

After storage, the specimens were de-bonded under tension using a universal testing machine (Model 4440 Instron, Canton, Mass., U.S.A.) at a cross-head speed of $0.5 \mathrm{~mm} /$ minute; ${ }^{33}$ bond strengths were expressed in $\mathrm{MPa}$. Bond failure sites were observed under 40x magnification (Olympus SZ40) in order to determine failure modes and were classified as follows: adhesive (failure between the dental tissue and the adhesive system), cohesive failures within the dental substrate, and cohesive failures within the resin composite. Specimens that presented two or more fracture types were classified as mixed failures. ${ }^{32}$

\section{RESULTS}

Regarding the enamel, the one-way ANOVA was performed to compare all experimental groups with the control, and a statistically significant difference between the tested groups was detected ( $F=47.28$ and $P<.05)$. Tukey's multiple comparisons test showed that Groups 1-4 (G1, G2, G3, and G4) presented the same bonding performance. However, G5 showed a statistically significant difference in bond strength when compared to the other experimental groups (Table 2).

Regarding the dentine, one-way ANOVA also detected a statistically significant difference between the tested groups ( $F=64.20$ and $P<.05)$. Tukey's multiple comparisons test showed that G6, G7, and G8 were statistically similar with the higher bond results, while G9 demonstrated more intermediate bond strength than the dentine control group. G10 showed the lowest bond strength of all the tested groups (Table 2).

A two-way ANOVA of enamel bond strengths for tested conditions shows that the factor step in the bonding sequence when contamination occurred (before the acidic primer and after the bonding resin) ( $F=55.53$ and $P<.05)$, the contamination treatment (blot dry or rinse-and-dry treatment) ( $F=66.46$ and $P<.05)$, and their interactions
( $F=31.64$ and $P<.05)$ were statistically significant. It was observed that, prior to primer application; similar results were obtained when the contamination was blot-dried or rinsed then dried. On the other hand, when contamination treatments were tested after the bonding resin application, higher bond strength values were obtained for the rinseand-dry cleaning procedure, which were similar to values observed in the control group (without contamination).

A two-way ANOVA of the dentine bond strengths for tested conditions shows that the factor step in the bonding sequence when contamination occurred (before the acidic primer and after the bonding resin) ( $F=262.23$ and $P<.05)$, contamination treatment (dry or rinse-and-dry treatment) ( $F=14.07$ and $P<.05)$, and their interactions $(F=23.41$ and $P<.05)$ were statistically significant. Dentine results revealed that before primer application, similar values were obtained when the contamination was blot dried or rinsed then dried. In contrast, when contamination treatments were tested after the application of bonding resin, higher bond strength values were obtained for the rinse-and-dry cleaning procedure, although it is important to note that these values are still lower than those observed in the control group (without contamination).

The type of fractures analysis indicated the prevalence of adhesive and mixed failures (Figure 2).

\section{DISCUSSION}

Saliva and blood contamination is a major clinical problem during restorative dental treatment, ${ }^{18,35}$ especially when rubber dam isolation is not feasible. ${ }^{1,13,18,19,26,27,34}$ Sub-gingival preparation margins are considered to be particularly prone to blood contamination during clinical procedures, ${ }^{2-6,8}$ which may lead to microleakage and secondary caries formation. ${ }^{26}$

Studies concerning to the effects of different contaminants - such as, water, saliva, plasma, handpiece lubricant, eugenol-based cement, and non-eugenol cement - on the adhesion of bonding agents to dental tissues ${ }^{7,11,16}$ show that plasma lowers both enamel (33\%) and dentine (70\%) bond strengths. Authors ${ }^{7,13}$ postulate that the protein content of some contaminants can prevent monomers from penetrating into both enamel reten- 
tions and acid exposed dentine collagen networks, thus reducing bond strength.

The adhesive system, time points of contamination, substrate type, blood type (fresh or with anticoagulants), and outcome variables vary in studies that investigate the effects of blood contamination on adhesive restorations, rendering comparisons complex and unclear. ${ }^{26,34}$

In this study, freshly drawn blood was used as the contaminant because previous studies ${ }^{34}$ report that the addition of an anticoagulant may decrease bond strength.

Self-etching adhesive systems have become very popular due to their rapid application; a lower number of components and operatory steps; the "no-rinse" concept, which eliminates the prob-

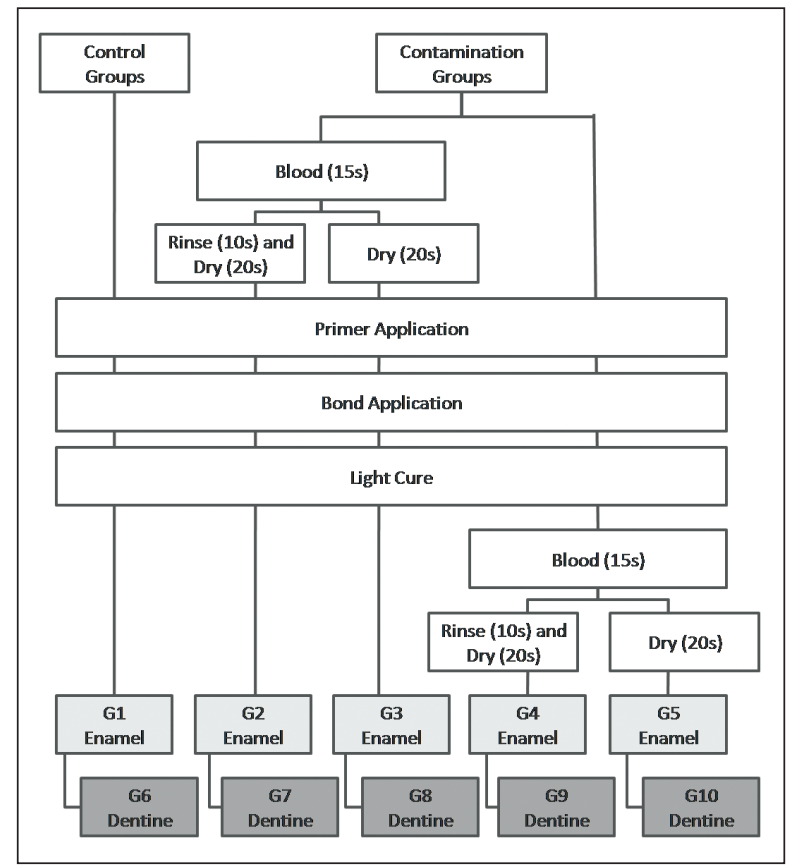

Figure 1. Schematic representation of the experimental protocol.

Table 1. Experimental groups. lem of over-drying or over-wetting the dentine; a decrease of post-operative sensitivity; and the technique-sensitivity associated with bonding to a dehydrated collagen matrix. ${ }^{1,36-38}$ When cavity preparations are restored without the use of a rubber dam, gingival bleeding can occur after rinsing off the phosphoric acid gel, coincidentally coming into contact with cavosurface margins; this does not occur when a self-etch adhesive is used. ${ }^{8}$

Experimental comparative studies of various self-etching systems that assess bond strength demonstrate the superior adhesive performance of Clearfil SE Bond to enamel and superficial/deep dentine. ${ }^{39}$ Thus, an evaluation of blood contamination effects in this specific adhesive system is fundamental.

The majority of enamel studies associated with blood contamination have evaluated bond strength for orthodontic purposes; the results are based on the suggestions of Reynolds ${ }^{40}$ that minimum bond strength, between 6 to $8 \mathrm{MPa}$, was able to withstand orthodontic forces. The studies from restorative dentistry disagree, suggesting ${ }^{41}$ that a bond

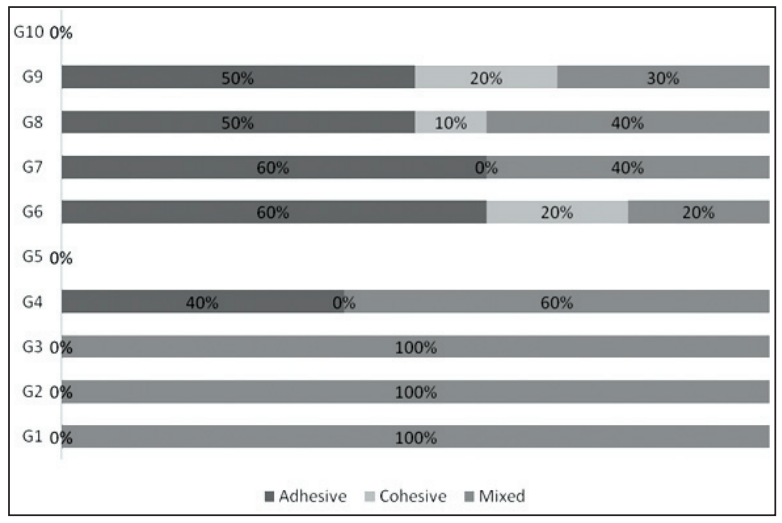

Figure 2. Incidence of the failure mode.

\begin{tabular}{lccccc}
\hline & \multicolumn{2}{c}{$\begin{array}{c}\text { Contamination before SES } \\
\text { (before acidic primer) }\end{array}$} & \multicolumn{2}{c}{$\begin{array}{c}\text { Contamination after SES } \\
\text { (after bonding resin) }\end{array}$} \\
Substrate & No contamination & Rinse-and-dry & Blot dry & Rinse-and-dry & Blot dry \\
\hline Enamel & G1 & $G 2$ & $G 3$ & $G 4$ & G5 \\
Dentine & G6 & G7 & G8 & G9 & G10 \\
\hline
\end{tabular}

Table 2. Tensile bond strengths for tested groups (Mean \pm SD, MPa). Same letters indicate no statistically significant difference within each row based on Tukey test (P $\leq .05$ ).

\begin{tabular}{|c|c|c|c|c|c|}
\hline \multirow[b]{2}{*}{ Substrate } & \multirow[b]{2}{*}{ No contamination } & \multicolumn{2}{|c|}{$\begin{array}{l}\text { Contamination before SES } \\
\text { (before acidic primer) }\end{array}$} & \multicolumn{2}{|c|}{$\begin{array}{l}\text { Contamination after SES } \\
\text { (after bonding resin) }\end{array}$} \\
\hline & & Rinse-and-dry & Blot dry & Rinse-and-dry & Blot dry \\
\hline Enamel & $\begin{array}{c}\text { G1 } \\
(21.0 \pm 3.7) \mathrm{A}\end{array}$ & $\begin{array}{c}\mathrm{G} 2 \\
(19.4 \pm 5.0) \mathrm{A}\end{array}$ & $\begin{array}{c}\mathrm{G} 3 \\
(16.2 \pm 5.6) \mathrm{A}\end{array}$ & $\begin{array}{c}\mathrm{G} 4 \\
(17.1 \pm 2.3) \mathrm{A}\end{array}$ & $\begin{array}{c}\text { G5 } \\
(0.0 \pm 0.0) B\end{array}$ \\
\hline Dentine & $\begin{array}{c}G 6 \\
(23.2 \pm 6.1) a\end{array}$ & $\begin{array}{c}G 7 \\
(23.0 \pm 4.1) a\end{array}$ & $\begin{array}{c}G 8 \\
(24.3 \pm 5.6) a\end{array}$ & $\begin{array}{c}\text { G9 } \\
(10.0 \pm 2.3) b\end{array}$ & $\begin{array}{c}G 10 \\
(0.0 \pm 0.0) c\end{array}$ \\
\hline
\end{tabular}


strength of 17-20 MPa is required to sufficiently resist contraction forces in order to attain gap-free margins of resin composite restorations. In this context, several studies examine blood contamination, but studies that specifically test self-etching systems for restorative purpose are limited. 19,23,26

Enamel results of this study reveal that blood contamination does not reduce bond strength when contamination occurs prior to primer application, which is in accordance with the findings of other authors. ${ }^{3,32}$ One explanation for this result is that the application of self-etch primer cleans or hydrolyzes blood on the enamel surface. ${ }^{3}$ Procedures for cleaning blood contamination - blot dry and rinse-and-dry - produce adhesion that is similar to that of the control group, suggesting that the acidic primer itself is able to clean blood from enamel surface and bond to underlying tissue.

According to our findings, blood contamination following the application of bonding resin was more involved; in order to recover reduced adhesion, it is imperative to rinse the contaminated enamel surface with a water spray in order to achieve the increased adhesion that effectively recovers bonding performance. When the blot dry procedure is performed, blood appears to be a physical barrier that impairs the mechanical retention of adhesive resin.

Our dentine results confirm that when blood contamination occurred before self-etch primer application, both the rinse-and-dry and blot dry techniques do not affect bond strength, which is in accordance with the findings of other authors. ${ }^{23}$ It can therefore be suggested, along with the reasoning of Oonsombat et $\mathrm{al}^{3}{ }^{3}$ that both cleaning procedures are able to remove blood from the dentinal surface and that the acidic primer itself can clean the blood and bond to the dentine surface. Conversely, some authors ${ }^{42}$ believe that when adhesive resin is added to a contaminated surface, the material's bond strength may be decreased.

When blood contamination occurs after the bonding resin has been cured, very different results were observed. When blood was rinsed away with water, increased bonding performance was observed; ${ }^{23}$ it is important to point out, however, that the rinse-and-dry treatment improves bonding but does not match the values of the control group. This may be due to the limited total thickness of the bonding resin ${ }^{13}$ or to the fact that rins- ing can disrupt the oxygen-inhibited and non-polymerized layer. However, the effects of disruption of the non-polymerized layer is still unclear. ${ }^{19}$

Our study shows that the blot dry cleaning procedure results in the worst bonding to dentine, which was already reported by other authors. ${ }^{13,19}$ We nonetheless agree that the remaining blood protein impairs proper adhesion and copolymerization of the adhesive and resin composite. ${ }^{19}$ Even when using self-etch adhesive systems, we consider the use of rubber dam essential to success in clinical procedures. Moreover, other studies are needed in order to test the efficacy of different substances that can counteract the deleterious effect of blood contamination without impairing the adhesion of self-etching system to the tooth structure.

\section{CONCLUSIONS}

Within the limits of the current investigation, the following may be concluded:

- Blood contamination impairs adhesion of the two-step self-etching system in enamel and dentine.

- The blot dry procedure did not clean the blood contaminated substrates where bonding resin was applied.

- The rinse-and-dry treatment proposed in this study can recover adhesion to enamel prior to the step in the bonding sequence when contamination occurred.

\section{ACKNOWLEDGMENTS}

This study was supported in part by Grants Fapesp 05/04701-7 and 06/05684-1.

\section{REFERENCES}

1. Yazici AR, Tuncer D, Dayangac B, Ozgunaltay G, Onen A. The effect of saliva contamination on microleakage of an etch-and-rinse and a self-etching adhesive. J Adhes Dent 2007;9:305-309.

2. Reddy L, Marker VA, Ellis E, 3rd. Bond strength for orthodontic brackets contaminated by blood: composite versus resin-modified glass ionomer cements. J Oral Maxillofac Surg 2003;61:206-213.

3. Oonsombat C, Bishara SE, Ajlouni R. The effect of blood contamination on the shear bond strength of orthodontic brackets with the use of a new self-etch primer. Am J Orthod Dentofacial Orthop 2003;123:547-550. 
4. Sfondrini MF, Cacciafesta V, Scribante A, De Angelis $M$, Klersy $C$. Effect of blood contamination on shear bond strength of brackets bonded with conventional and self-etching primers. Am J Orthod Dentofacial Orthop 2004; 125:357-360.

5. Sayinsu K, Isik F, Sezen S, Aydemir B. Light curing the primer-beneficial when working in problem areas? Angle Orthod 2006;76:310-313.

6. Oztoprak MO, Isik F, Sayinsu K, Arun T, Aydemir B. Effect of blood and saliva contamination on shear bond strength of brackets bonded with 4 adhesives. Am J Orthod Dentofacial Orthop 2007;131:238-242.

7. Pashley EL, Tao L, Mackert JR, Pashley DH. Comparison of in vivo vs. in vitro bonding of composite resin to the dentin of canine teeth. J Dent Res 1988;67:467-470.

8. Schattenberg A, Werling U, Willershausen B, Ernst CP. Two-year clinical performance of two one-step self-etching adhesives in the restoration of cervical lesions. Clin Oral Investig 2008;12:225-232.

9. Joynt RB, Davis EL, Schreier PH. Rubber dam usage among practicing dentists. Oper Dent 1989;14:176-181.

10. Strydom C. Handling protocol of posterior composites Rubber Dam. SADJ 2005;60:292-293.

11. Barakat MM, Powers JM. In vitro bond strength of cements to treated teeth. Aust Dent J 1986;31:415-419.

12. Powers JM, Finger WJ, Xie J. Bonding of composite resin to contaminated human enamel and dentin. J Prosthodont 1995;4:28-32

13. Peschke A, Blunck U, Roulet JF. Influence of incorrect application of a water-based adhesive system on the marginal adaptation of Class V restorations. Am J Dent 2000;13:239244.

14. Fritz UB, Finger WJ, Stean H. Salivary contamination during bonding procedures with a one-bottle adhesive system. Quintessence Int 1998;29:567-572.

15. el-Kalla IH, Garcia-Godoy F. Saliva contamination and bond strength of single-bottle adhesives to enamel and dentin. Am J Dent 1997;10:83-87.

16. Johnson ME, Burgess JO, Hermesch CB, Buikema DJ. Saliva contamination of dentin bonding agents. Oper Dent 1994:19:205-210

17. Xie J, Powers JM, McGuckin RS. In vitro bond strength of two adhesives to enamel and dentin under normal and contaminated conditions. Dent Mater 1993;9:295-299.

18. Abdalla Al, Davidson CL. Bonding efficiency and interfacial morphology of one-bottle adhesives to contaminated dentin surfaces. Am J Dent 1998;11:281-285.

19. Sattabanasuk V, Shimada Y, Tagami J. Effects of saliva contamination on dentin bond strength using all-in-one adhesives. J Adhes Dent 2006;8:311-318.
20. Yoo HM, Pereira PN. Effect of blood contamination with 1-step self-etching adhesives on microtensile bond strength to dentin. Oper Dent 2006;31:660-665.

21. van Schalkwyk JH, Botha FS, van der Vyver PJ, de Wet FA, Botha SJ. Effect of biological contamination on dentine bond strength of adhesive resins. SADJ 2003;58:143-147.

22. Pashley $\mathrm{DH}$. Dentin bonding: overview of the substrate with respect to adhesive material. J Esthet Dent 1991;3:46-50.

23. Miles DA, Anderson RW, Pashley DH. Evaluation of the bond strength of dentin bonding agents used to seal resected root apices. J Endod 1994;20:538-541.

24. Kaneshima T, Yatani H, Kasai T, Watanabe EK, Yamashita A. The influence of blood contamination on bond strengths between dentin and an adhesive resin cement. Oper Dent 2000;25:195-201.

25. Hobson RS, Ledvinka J, Meechan JG. The effect of moisture and blood contamination on bond strength of a new orthodontic bonding material. Am J Orthod Dentofacial Orthop 2001;120:54-57.

26. Faltermeier A, Behr M, Rosentritt M, Reicheneder C, Müssig D. An in vitro comparative assessment of different enamel contaminants during bracket bonding. Eur J Orthod 2007;29:559-563.

27. Eiriksson SO, Pereira PN, Swift EJ, Heymann HO, Sigurdsson A. Effects of blood contamination on resin-resin bond strength. Dent Mater 2004;20:184-190.

28. Dietrich T, Kraemer M, Losche GM, Wernecke KD, Roulet JF. Influence of dentin conditioning and contamination on the marginal integrity of sandwich Class II restorations. Oper Dent 2000;25:401-410.

29. Sayinsu K, Isik F, Sezen S, Aydemir B. Effect of blood and saliva contamination on bond strength of brackets bonded with a protective liquid polish and a light-cured adhesive. Am J Orthod Dentofacial Orthop 2007;131:391-394.

30. Itoh T, Fukushima T, Inoue $\mathrm{Y}$, Matsuo N, Matsumoto $\mathrm{M}$. Bond strength of brackets cemented with light-cured glass-ionomer cements to contaminated enamel. Am J Dent 2000;13:181-186.

31. Cacciafesta V, Sfondrini MF, Scribante A, De Angelis M, Klersy $\mathrm{C}$. Effects of blood contamination on the shear bond strengths of conventional and hydrophilic primers. Am J Orthod Dentofacial Orthop 2004;126:207-212.

32. Cacciafesta V, Sfondrini MF, Scribante A, De Angelis M, Klersy $C$. Effect of blood contamination on shear bond strength of brackets bonded with a self-etching primer combined with a resin-modified glass ionomer. Am J Orthod Dentofacial Orthop 2004;126:703-708. 
33. Kirovski I, Madzarova S. Tensile bond strength of a lightcured glass ionomer cement when used for bracket bonding under different conditions: an in vitro study. Eur J Orthod 2000;22:719-723.

34. Dietrich T, Kraemer ML, Roulet JF. Blood contamination and dentin bonding--effect of anticoagulant in laboratory studies. Dent Mater 2002;18:159-162.

35. Ernst CP, Brandenbusch M, Meyer G, Canbek K, Gottschalk F, Willershausen B. Two-year clinical performance of a nanofiller vs a fine-particle hybrid resin composite. Clin Oral Investig 2006;10:119-125.

36. De Munck J, Van Landuyt K, Peumans M, et al. A critical review of the durability of adhesion to tooth tissue: methods and results. J Dent Res 2005;84:118-132.

37. Van Meerbeek B, Perdigão J, Lambrechts $P$, Vanherle G. The clinical performance of dentin adhesives. J Dent 1998:1-20.

38. Tay FR, Pashley DH. Have dentin adhesives become too hydrophilic? J Can Dent Assoc 2003;69:726-731.

39. Kaaden C, Powers JM, Friedl KH, Schmalz G. Bond strength of self-etching adhesives to dental hard tissues. Clin Oral Investig 2002;6:155-160.

40. Reynolds IR. A review of direct orthodontic bonding. $\mathrm{Br} \mathrm{J}$ Orthod 1975;2:171-178.

41. Davidson CL, de Gee AJ, Feilzer A. The competition between the composite-dentin bond strength and the polymerization contraction stress. J Dent Res 1984;63:1396-1399.

42. Benderli Y, Gokce K, Buyukgokcesu S. In vitro shear bond strength of adhesive to normal and fluoridated enamel under various contaminated conditions. Quintessence Int 1999;30:570-575. 